KIDDER, G. W. \& DUtTA, B. N. (1958). J. gen. Microbiol. 18, 621-638

\title{
The Growth and Nutrition of Crithidia fasciculata
}

\author{
By G. W. KIDDER and B. N. DUTTA \\ Biological Laboratory, Amherst College, Amherst, Massachusetts, U.S.A.
}

\begin{abstract}
SUMMARY: The conditions for luxuriant axenic cultivation of the trypanosomid flagellate Crithidia fasciculata in chemically-defined media were determined. Improvements over the hitherto published media include higher concentrations of amino acids, folic acid (where this is the sole source of pteridine) and purines and the inclusion of threonine and Tween 80. Increased oxygenation was obtained by incubating liquid cultures in tubes in a sloped position. Under these conditions consistently excellent growth (up to $2 \times 10^{8}$ organisms $/ \mathrm{ml}$.) was obtained and the useful incubation period could be decreased to 4 days. Using the improved medium, qualitative and quantitative studies on the nutritional requirements of the organism were carried out. Growth failed when any one of the following amino acids was omitted from the basal medium: histidine, phenylalanine, isoleucine, leucine, valine, lysine, arginine, tyrosine, methionine, tryptophan. The omission of threonine caused drastically decreased growth rates and lower yields. It was found that phenylpyruvic acid could replace phenylalanine; cysteine, cystathionine or homocysteine could replace methionine; and citrulline, but not ornithine, could replace arginine for $C$. fasciculata. In addition to the amino acid requirements a nutritional need for the following was demonstrated: a carbohydrate, haemin, a purine, thiamine, riboflavin, pantothenic acid, nicotinic acid or its amide, pyridoxal or pyridoxamine, biotin, folic acid and an unconjugated pteridine (biopterin). The natural purines, their nucleosides and nucleotides are nearly equivalent, on a molar basis, in growth promotion. Numerous substituted purines were also tested for their ability to supply the purine requirement. No exogenous source of pyrimidine for nucleic acid synthesis is necessary provided folic acid is present. Folic acid can be omitted from the growth medium provided thymine and methionine are present. The absolute requirement for biotin could not be demonstrated in the present medium without the use of avidin.
\end{abstract}

Crithidia fasciculata, a trypanosomid parasite of the mosquito, has been the subject of a large number of reports. Unfortunately considerable confusion has resulted because of the differences in naming which have appeared (see Wallace, 1943). Biochemical interest in this organism was initiated over twenty years ago when Marguerite Lwoff (1933) showed that it (referred to as Strigomonas fasciculata) could be grown in peptone water to which blood or haemin had been added. Recently a number of papers have appeared setting forth cultural conditions and organic requirements of this organism (Cowperthwaite, Weber, Packer \& Hutner, 1953; Nathan \& Cowperthwaite, 1954; Broquist \& Albrecht, 1955). While the Lederle group (Broquist \& Albrecht, 1955; Patterson et al. 1955) opened up a new field in showing the nutritional importance of an unconjugated pteridine (which they called biopterin) they (Broquist \& Albrecht, 1955) report inconsistent growth in the medium of Nathan \& Cowperthwaite (1954) which ultimately became so poor as to lose its usefulness (Dr H. P. Broquist, personal communication). 
Our attempts to utilize Crithidia fasciculata for metabolic studies were hampered by the poor and inconsistent growth obtained in any of the previously published defined media. We therefore undertook a systematic search for the chemical and physical conditions which would permit rapid and abundant growth of the organism. This report describes modified chemically-defined media for $C$. fasciculata which allow for consistent analysis of the nutritional and metabolic patterns of the organism. Using these improved conditions we have examined the quantitative nitrogen and growth factor requirements of C. fasciculata. While the qualitative amino acid and growth factor requirements of this organism have been recently described (Cowperthwaite et al. 1953; Aaronson \& Nathan, 1954; Nathan \& Cowperthwaite, 1955; Nathan, Hutner \& Levin, 1956), quantitative studies are largely limited to the pteridines (Broquist \& Albrecht, 1955; Nathan et al. 1956).

\section{METHODS}

The strain of Crithidia fasciculata used in this study was obtained from Dr H. P. Broquist (Lederle Division of American Cyanamid Co., Pearl River, N.Y.). For stock cultures we used a crude medium consisting of $2 \%(\mathrm{w} / \mathrm{v})$ proteose-peptone, $0 \cdot 1 \%(\mathrm{w} / \mathrm{v})$ Liver Fraction L (Wilson), $1 \%(\mathrm{w} / \mathrm{v})$ glucose, $0.0025 \%(\mathrm{w} / \mathrm{v})$ haemin (in triethanolamine), and $0.00025 \%(\mathrm{w} / \mathrm{v})$ folic acid. This medium was adjusted to $\mathrm{pH} 8$ and was sterilized by autoclaving at $120^{\circ}$ for $15 \mathrm{~min}$. While stock cultures can be transplanted at weekly intervals or longer, in practice we found it convenient to make daily transplants so that inoculation organisms of suitable age for experimental use were always available.

In making up the various experimental media, it was found convenient to prepare concentrated solutions of the various components or groups of similar components for final compounding. In this way a medium lacking any desired component could be prepared with ease. The concentrated solutions were layered with toluene and stored at refrigerator temperatures. Tyrosine and guanine, having low solubilities in water, could not be kept in concentrated solutions and were prepared in dilute solutions just before use and added in the desired concentrations. Later this disadvantage was overcome by using tyrosine ethyl ester and guanylic acid, both of which are more soluble. The haemin solution was prepared (at no greater than monthly intervals) in triethanolamine $(50 \%, \mathrm{w} / \mathrm{v})$. When the basal medium was adjusted to $\mathrm{pH} 8 \cdot 1$ little difficulty was encountered with haemin precipitation.

The basal medium, without glucose, Tween and the compound under investigation, was routinely made up to double strength and distributed in $2 \mathrm{ml}$. quantities in $15 \times 125 \mathrm{~mm}$. test tubes. Appropriate dilutions of the test compound (variable) were added in $1 \mathrm{ml}$. quantities (in triplicate) to tubes which were aluminium capped before sterilization. Test substances which were unstable to heat were added later after filter sterilization of appropriate dilutions. The glucose and Tween was made up to a fourfold concentration, and after sterilization by autoclaving, the flasks were cooled under running 


\section{Growth and nutrition of Crithidia}

water with shaking to prevent the Tween from separating out. The flask containing the glucose + Tween solution was then inoculated with a 4- to 5-day culture so that the concentration of the inoculum was $1 / 400$ of final medium. One ml. quantities of this inoculated solution were then added aseptically to each tube, bringing the total volume in each tube to $4 \mathrm{ml}$.

When glucose or Tween was to be tested it was omitted from the standard inoculum and was autoclaved separately and added aseptically to the tubes.

After inoculation the tubes were incubated at $25^{\circ}$ in a sloped position. Growth was estimated by determining the optical density at wavelength $650 \mathrm{~m} \mu$. by a Lumetron colorimeter.

Crithidia fasciculata tended to settle to the bottom of the tubes and to adhere to their sides. Considerable shaking was required to obtain a uniform suspension for optical density determinations. By coating the tubes with silicone according to the directions given for Siliclad (Clay-Adams, Inc., New York, N.Y.) this tendency was greatly decreased and the time required for making turbidimetric readings markedly shortened.

As the presence of haemin somewhat coloured the medium, uninoculated tubes of the medium under test were used as the blanks when readings were being made. In many experiments the correlation between the turbidity and the number of organisms $/ \mathrm{ml}$. was established by comparing optical density with haemocytometer counts.

For the quantitative determinations of the amino acids and of certain of the growth factors, organisms for inoculation could be taken directly from stock medium with no appreciable carry-over. This would indicate low storage in the organism together with relatively high requirements. Preparation of depleted organisms for inoculation was not necessary when carrying out doseresponse studies on carbohydrates, haemin, amino acids, purines, thiamine, riboflavin, pantothenic acid and nicotinamide, as essentially no growth resulted in the first transplants when any one of these factors was missing from the medium.

For studies on pyridoxal or pyridoxamine the organisms used for the inoculum were depleted by allowing them to grow in the defined medium without added vitamin $\mathbf{B}_{6}$ components. When organisms were transplanted from stock medium (even after thorough washing) into such a deficient medium there was appreciable growth due to carry-over, but this growth failed in the second transfer. By using these vitamin $\mathbf{B}_{\mathbf{6}}$-depleted organisms essentially zero blanks were obtained in dose-response experiments, and the organisms responded to added pyridoxal and pyridoxamine in a regular and reproducible manner.

In studies on folic acid and biopterin the preparation of the inoculum was very critical for reproducible results. Storage of these pteridines within the organisms made washing of the inoculum of little use, as fairly good growth resulted in the first transplant to a medium devoid of added pteridines; this situation parallels that with Tetrahymena and folic acid (Kidder \& Fuller, 1946). After testing many depletion conditions it was found that the best results were obtained by growing inoculum organisms for 10-11 days in 
Medium I (Table 1) in which the folic acid concentration had been decreased to $0.001 \mu \mathrm{g} . / \mathrm{ml}$. While the number of organisms produced (first transfer) was not very different from Medium I minus folic acid, they appeared to be in better physiological condition and responded in a more dependable manner.

\section{Table 1. Composition of media}

Medium $I$ is the complete medium used in most of the experiments. Medium II is the final medium recommended for Crithidia fasciculata. All figures represent $\mu \mathrm{g}$. $/ \mathrm{ml}$. final concentration.

\begin{tabular}{|c|c|c|c|c|c|}
\hline Components & $\begin{array}{c}\text { Medium } \\
\text { I } \\
(\mu \mathrm{g} . / \\
\mathrm{ml} .)\end{array}$ & $\begin{array}{l}\text { Medium } \\
\text { II } \\
(\mu \mathrm{g} . / \\
\text { ml. })\end{array}$ & Components & $\begin{array}{c}\text { Medium } \\
\text { I } \\
(\mu \mathrm{g} . / \\
\text { ml. })\end{array}$ & $\begin{array}{c}\text { Medium } \\
\text { II } \\
(\mu \mathrm{g} . / \\
\text { ml. })\end{array}$ \\
\hline L-Arginine $\mathbf{H C l}$ & 430 & 430 & Cobalamin & \multicolumn{2}{|l|}{0.001} \\
\hline L-Histidine $\mathbf{H C l}$ & 210 & 210 & Folic acid & \multirow[t]{2}{*}{1} & \multirow[t]{2}{*}{2} \\
\hline DL-Isoleucine & 630 & 630 & & & \\
\hline L-Leucine & 970 & 970 & Adenine & \multicolumn{2}{|r|}{50} \\
\hline L-Lysine $\mathbf{H C l}$ & 760 & 760 & Guanine & \multicolumn{2}{|r|}{ - } \\
\hline DL-Methionine & $\mathbf{3 4 0}$ & 340 & Xanthine & \multicolumn{2}{|r|}{-} \\
\hline L-Phenylalanine & 500 & 500 & Uracil & \multicolumn{2}{|r|}{ - } \\
\hline DL-Threonine & 440 & 440 & Cytidylic acid & \multirow{2}{*}{\multicolumn{2}{|c|}{-}} \\
\hline L-Tryptophan & 120 & 120 & & & \\
\hline DL-Valine & 660 & 660 & Haemin & \multirow{2}{*}{\multicolumn{2}{|c|}{$\begin{array}{l}25 \\
50\end{array}$}} \\
\hline L-Tyrosine & 200 & - & Triethanolamine & & \\
\hline L-Tyrosine ethyl ester & - & 200 & & \multirow{2}{*}{\multicolumn{2}{|c|}{10,000}} \\
\hline DL-Alanine & $\mathbf{5 5 0}$ & - & Glucose & & \\
\hline L-Aspartic acid & 610 & 一 & & \multirow{2}{*}{\multicolumn{2}{|c|}{$\mathbf{5 , 0 0 0}$}} \\
\hline Glycine & 50 & - & Tween 80 & & \\
\hline L-Glutamic acid & 1,165 & - & & \multirow{3}{*}{\multicolumn{2}{|c|}{700}} \\
\hline L-Proline & 770 & - & Ethylenediamine- & & \\
\hline DL-Serine & 440 & 一 & tetraacetic acid & & \\
\hline$p$-Aminobenzoic acid & 3 & - & $\mathrm{NaCl}$ & 4,000 & 4,000 \\
\hline Biotin & 0.2 & $0 \cdot 2$ & $\mathrm{Na}_{2} \mathrm{HPO}_{4}$ & 1,250 & 1,250 \\
\hline Choline Cl & 3 & 3 & $\mathrm{KH}_{2} \mathrm{PO}_{4}$ & 500 & 500 \\
\hline Inositol & 3 & - & $\mathrm{MgSO}_{4} \cdot 7 \mathrm{H}_{2} \mathrm{O}$ & 400 & 400 \\
\hline Nicotinamide & 5 & $\mathbf{5}$ & $\mathrm{FeSO}_{4} \cdot 7 \mathrm{H}_{2} \mathrm{O}$ & $4 \cdot 9$ & $4 \cdot 9$ \\
\hline Pyridoxine $\mathrm{HCl}$ & 2 & 一 & $\mathrm{CaCl}_{2} \cdot 2 \mathrm{H}_{2} \mathrm{O}$ & $7 \cdot 3$ & $7 \cdot 3$ \\
\hline Pyridoxal HCl & $\mathbf{2}$ & $\mathbf{2}$ & $\mathrm{Na}_{2} \mathrm{M} \circ \mathrm{O}_{4} \cdot 2 \mathrm{H}_{2} \mathrm{O}$ & $10 \cdot 1$ & $10 \cdot 1$ \\
\hline Pyridoxamine $2 \mathrm{HCl}$ & $\mathbf{2}$ & 2 & $\mathrm{ZnSO}_{4}$ & 68 & 68 \\
\hline Ca pantothenate & 8 & 8 & $\mathrm{MnSO}_{4} \cdot \mathrm{H}_{2} \mathrm{O}$ & 77 & 77 \\
\hline Riboflavin & 2 & 2 & $\mathrm{CoSO}_{4} \cdot 7 \mathrm{H}_{2} \mathrm{O}$ & $\mathbf{2} \cdot \mathbf{4}$ & $2 \cdot 4$ \\
\hline Thiamine & 2 & 2 & $\mathrm{CuSO}_{4} \cdot 5 \mathrm{H}_{2} \mathrm{O}$ & 1 & 1 \\
\hline & & & $\mathrm{H}_{3} \mathrm{BO}_{3}$ & $0 \cdot 7$ & 0.7 \\
\hline & & & KI & 0.03 & 0.03 \\
\hline
\end{tabular}

All experiments involving light-sensitive compounds (riboflavin, pyridoxal, pyridoxamine, pteridines and pteridine conjugates) were handled in the absence of white light to minimize their inactivation, and all experimental cultures were incubated in total darkness.

\section{RESULTS}

By varying the total amino acid concentration of the medium it was soon found that Crithidia fasciculata required a much higher concentration of these components than had previously been used. The original starting-point was 
the concentrations and proportions used in the studies on Tetrahymena pyriformis (Dewey, Parks \& Kidder, 1950). The final concentrations found to be satisfactory are given in Table 1, Medium I. With this basal medium, and with appropriate omissions, other components were studied.

It was found that an exogenous source of carbohydrate was necessary for growth, and glucose satisfied this requirement. From dose-response studies it was found advantageous to add $10 \mathrm{mg}$. glucose $/ \mathrm{ml}$. and additional quantities (up to $20 \mathrm{mg} . / \mathrm{ml}$.) had no further stimulating effect.

As reported by Marguerite Lwoff (1933), haemin was found to be an absolute requirement for Crithidia fasciculata. Growth was in proportion to graded amounts of haemin up to a concentration of $25 \mu \mathrm{g} . / \mathrm{ml}$.; further increases were without effect. Ferrichrome, an iron-chelate compound isolated from Ustilago sphaerogena, was reported to replace haemin for the growth of a fungus, Pilobolus sp., and was about 500 times more active (Nielands, 1952, 1953). We obtained some ferrichrome from Dr J. B. Nielands (Department of Biochemistry, University of California, Berkeley), but found that it had no haeminreplacing activity for $C$. fasciculata.

Experiments with triethanolamine in concentrations from 1 to $10 \mathrm{mg} . / \mathrm{ml}$. showed that it was inert as far as influencing growth was concerned. It is advantageous, however, to include it in the medium as it tends to keep the haemin in solution (Cowperthwaite et al. 1953).

Tween 80 was found to be stimulatory to growth (Table 2), the optimum concentration being about $5 \mathrm{mg} . / \mathrm{ml}$; bovine serum-albumin fraction $\mathrm{V}$ had about the same effect as Tween. Unlike the case of Tetrahymena pyriformis (Kidder, Dewey \& Heinrich 1954), where it was found that the apparent stimulation by Tween was not due to increase in number of organisms, actual increase in number of organisms as well as greater optical density occurred with Crithidia fasciculata (Table 2). Both Tween and albumin appear to function here by virtue of their physical properties.

Table 2. Response of Crithidia fasciculata to Tween 80 and to albumin Basal Medium I minus Tween. Four-day growth.

\begin{tabular}{|c|c|c|c|c|}
\hline \multirow[b]{2}{*}{$\begin{array}{l}\text { Addition } \\
\text { (mg./ml.) }\end{array}$} & \multicolumn{2}{|c|}{ Tween 80} & \multicolumn{2}{|c|}{ Albumin } \\
\hline & $\begin{array}{l}\text { Optical } \\
\text { density }\end{array}$ & $\begin{array}{c}\text { Organisms } \\
\times 10^{6} / \mathrm{ml}\end{array}$ & $\begin{array}{l}\text { Optical } \\
\text { density }\end{array}$ & $\begin{array}{c}\text { Organisms } \\
\times 10^{6} / \mathrm{ml} .\end{array}$ \\
\hline 0 & 0.573 & 136 & 0.535 & 138 \\
\hline 1.0 & 0.683 & - & $0 \cdot 647$ & - \\
\hline $2 \cdot 0$ & 0.703 & - & 0.687 & - \\
\hline 5.0 & 0.733 & 205 & 0.728 & 200 \\
\hline $10 \cdot 0$ & $0 \cdot 730$ & - & 0.722 & - \\
\hline
\end{tabular}

To test the effect of increasing the surface area of the cultures to give better aeration, two sets of tubes containing identical medium and inoculum were incubated together, one set sloped (Kidder \& Dewey, 1948) and the other upright. Faster growth and higher yields were obtained in the sloped tubes.

In attempts to simplify the basal medium various changes were made which resulted in Medium II (Table 1). Tyrosine ethyl ester replaced tyrosine. 
adenine replaced the nucleic acid derivatives and the non-essential amino acids were omitted. In spite of the sharp decrease in total amino acid concentration no significant decrease in growth rate or total yields resulted. Decrease of the concentration of the essential amino acids, however, decreased growth, so that it would appear questionable whether the non-essential amino acids are indeed utilized. With Medium II (Table 1) average optical densities of 0.720 were obtained by 4 days as compared to 0.060 obtained when the medium of Nathan \& Cowperthwaite (1954) was used. An optical density of 0.733 represents over 200 million organisms/ml. (Table 2 ).

\section{Amino acid studies}

When satisfactory growth of Crithidia fasciculata was finally obtained attention was turned to specific amino acids. By using Medium $I$ the specific amino acid requirements of the organism were determined by the omission technique. Growth failed when any one of the following amino acids was omitted from the medium: histidine, isoleucine, leucine, lysine, methionine, valine, arginine, phenylalanine, tryosine and tryptophan. This confirms the earlier findings of Cowperthwaite et al. (1953). These authors listed threonine as an essential amino acid but later (Hutner \& Provasoli, 1955) it was stated that threonine was essential only when adenine was the sole source of purine, but was non-essential when adenosine was added. Nathan \& Cowperthwaite (1955) omitted threonine from their medium. We were unable to confirm the relationship between adenosine and threonine synthesis in $C$. fasciculata as we found slow and equal threonine synthesis (as evidenced by growth) in the presence of adenine or adenosine. As can be seen from Table 3, the organisms

Table 3. Growth of Crithidia fasciculata with or without threonine in the presence and absence of the non-essential amino acids

$\mathbf{A}=$ Medium I minus threonine; $\mathbf{B}=$ Medium I minus threonine and the non-essential amino acids. Growth indicated by optical density.

\begin{tabular}{|c|c|c|c|c|c|c|c|}
\hline \multirow{2}{*}{\multicolumn{2}{|c|}{$\begin{array}{l}\text { DL-Threonine } \\
(\mu \mathrm{g} . / \mathrm{ml} .)\end{array}$}} & \multicolumn{6}{|c|}{ Days } \\
\hline & & 4 & 5 & 6 & 7 & 8 & 10 \\
\hline $\mathbf{A}$ & $\begin{array}{r}0 \\
80\end{array}$ & $\begin{array}{l}0.225 \\
0.670\end{array}$ & $\begin{array}{l}0.285 \\
0.730\end{array}$ & $\begin{array}{l}0.354 \\
0.747\end{array}$ & $\begin{array}{l}0.486 \\
0.792\end{array}$ & $\begin{array}{l}0.560 \\
0.814\end{array}$ & $\begin{array}{l}0.620 \\
0.921\end{array}$ \\
\hline B & $\begin{array}{r}0 \\
80\end{array}$ & $\begin{array}{l}0.115 \\
0.681\end{array}$ & $\begin{array}{l}0.161 \\
0.735\end{array}$ & $\begin{array}{c}0 \cdot 190 \\
0 \cdot 760\end{array}$ & $\begin{array}{l}0.202 \\
0.790\end{array}$ & $\begin{array}{l}0.250 \\
0.800\end{array}$ & $\begin{array}{l}0.310 \\
0.910\end{array}$ \\
\hline
\end{tabular}

presumably synthesized threonine slowly and this degree of synthesis was enhanced by the non-essential amino acids. The non-essential amino acid responsible for the stimulation in threonine synthesis is glycine, for essentially the same results were obtained when only glycine was added to the essential amino acid mixture. This may indicate that threonine is synthesized (at least in part) by a reversal of the threonine aldolase reaction (Lin \& Greenberg, 1954) and that glycine is one of the limiting factors under these conditions. Under the most favourable conditions for threonine synthesis, however, the organism is very inefficient and the lack of exogenous threonine renders the medium far 
from optimal. We are unable to account for the growth obtained by Broquist \& Albrecht (1955) on the medium proposed by Nathan \& Cowperthwaite (1954) which contained a low concentration of essential amino acids, no nonessential amino acids and no threonine. Using an incubation period of 4-5 days, as they did, we have never been able to get appreciable growth in this medium. Nathan \& Cowperthwaite's (1954) growth results are somewhat easier to understand since they used 10- to 18-day growth periods and their turbidimetric unit (Welch Densichron) are over three times that which we use (comparison of the optical density readings of the Welch Densichron and our system was kindly made by Dr S. Aaronson of the Haskins Laboratories), so the high figures given are quite misleading.

$\alpha$-Aminobutyric acid was said to replace threonine with a tenfold efficiency (Hutner \& Provasoli, 1955). When this compound was tested over a wide range of concentrations in the present medium it was found to be without activity in this respect. On the other hand, $\gamma$-hydroxy- $\alpha$-aminobutyric acid (homoserine) substituted readily for threonine.

Homocysteine can replace methionine in the nutrition of Crithidia fasciculata (Hutner \& Provasoli, 1955). We have found this to be the case in the present medium with or without the addition of a methyl donor (choline, betaine), although added methyl donor improved the transmethylation reaction (Fig. 1). Cystine or cystathionine can likewise replace methionine, so it would appear that the organism possesses the enzymes of the commonly encountered system methionine $\rightarrow$ cysteine and possibly indicates that the reactions are reversible. While these responses are readily demonstrated in Media I and II, where the folic acid concentration is high, they do not occur when the organisms are growing on a low folic acid and biopterin medium, where methionine becomes an absolute requirement. This probably indicates that the transmethylation is mediated by a folic acid coenzyme, which is to be expected, and that large amounts of the vitamin are required for its formation. High concentrations of biopterin cannot replace the high folic acid requirement for this transmethylation.

Unlike most animal species so far reported, Crithidia fasciculata has a requirement for tyrosine as well as phenylalanine (Cowperthwaite et al. 1953), although similar requirements have been reported for Leishmania tarentolae (Trager, 1956), Paramecium aurelia (Miller \& van Wagtendonk, 1956) and P. multimicronucleatum (Johnson \& Miller, 1956). Phenylpyruvic acid can replace phenylalanine for the growth of $C$. fasciculata (Fig. 2), although the keto compound is less active than the amino acid.

When arginine was omitted from Medium I no growth of Crithidia fasciculata took place; citrulline replaced arginine for growth and appeared to be more active (Fig. 3). This is completely different from the case of Tetrahymena pyriformis (Kidder \& Dewey, 1951 ; Dewey, Heinrich \& Kidder, 1957), where it was found that citrulline spared, but never replaced, arginine. Ornithine was not active in $C$. fasciculata in replacing arginine. The fact that citrulline was more active than arginine for growth may suggest a separate function for citrulline, other than as a precursor of arginine. 
Many dose-response tests on the ten amino acids required by Crithidia fasciculata were carried out. Table 4 gives the amounts of each of these amino acids which had to be added to Medium I (minus the compound being tested)

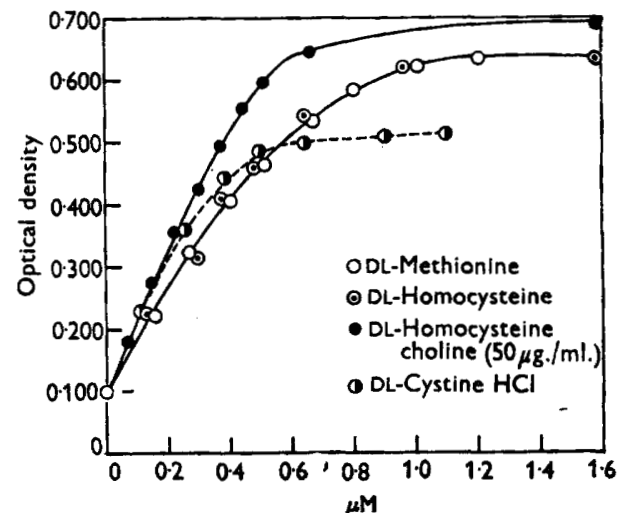

Fig. 1

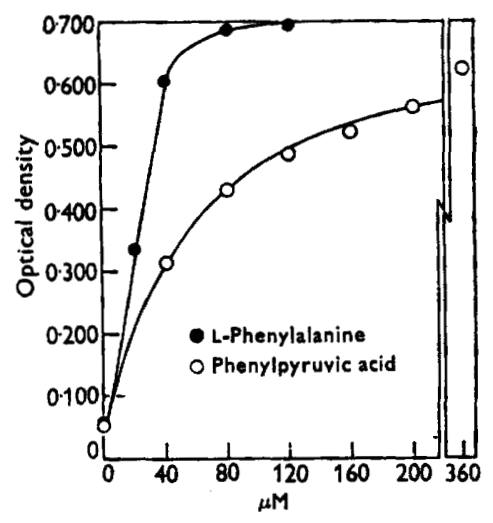

Fig. 2

Fig. 1. Response of Crithidia fasciculata to methionine, cysteine, homocysteine and homocysteine plus choline. Basal Medium I minus methionine. Four-day growth.

Fig. 2. Response of Crithidia fasciculata to phenylalanine and phenylpyruvic acid. Basal Medium I minus phenylalanine. Four-day growth

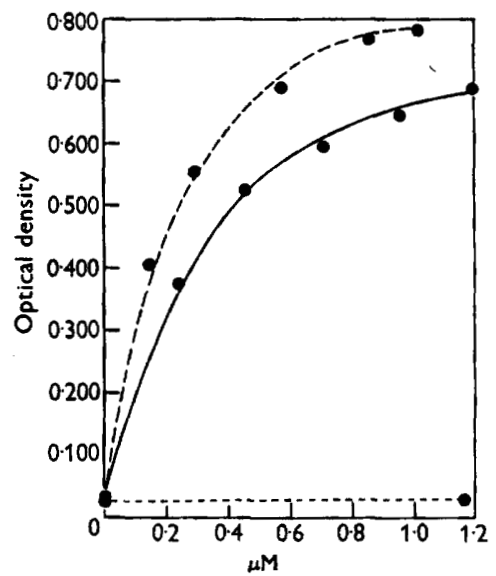

Fig. 3. Response of Crithidia fasciculata to arginine, citrulline and ornithine. Basal Medium I minus arginine. Four-day growth. Upper curve (dashed)=L-citrulline ; middle curve (solid) = L-arginine $\mathrm{HCl}$; lower curve $($ dotted) = $\mathbf{L}$-ornithine $\mathrm{HCl}$.

to bring about half maximal and maximal growth. Also included in Table 4 is the amount of threonine ('semi-essential') which must be added to produce maximal growth within a 4-day incubation period.

\section{Purines}

Crithidia fasciculata has been shown to have a purine requirement (Cowperthwaite et al. 1953; Aaronson \& Nathan, 1954). This requirement can be fully satisfied by any one of the natural purines (uric acid was not tested), their 
Table 4. Concentrations of amino acids required for half maximum and optimal growth of Crithidia fasciculata as determined in Medium I minus the amino acid being tested

\begin{tabular}{lcc}
\multicolumn{3}{c}{ Figures represent $\mu \mathrm{g} \cdot / \mathrm{ml}}$. \\
\multicolumn{1}{c}{ Amino acid } & Half & \\
maximal & Maximal \\
L-Histidine HCl & 20 & 80 \\
DL-Isoleucine & 16 & 80 \\
DL-Valine & 119 & 320 \\
L-Leucine & 85 & 200 \\
L-Lysine & 30 & 160 \\
L-Arginine HCl & 32 & 160 \\
L-Tyrosine & 56 & 350 \\
DL-Methionine & 19 & 60 \\
L-Tryptophan & 40 & 180 \\
DL-Threonine & $7 \cdot 3$ & 24 \\
\end{tabular}

* Slow and suboptimal growth without threonine.

Table 5 Comparison of the activities of free base, nucleosides and nucleotides in satisfying the purine requirement of Crithidia fasciculata

Figures represent the amount required for half maximum growth in Medium I minus all nucleic acid derivatives. Four-day growth.

$\begin{array}{lc} & \mu \mathrm{M} \\ \text { Adenine } & 0 \cdot 057 \\ \text { Adenosine } & 0 \cdot 063 \\ \text { Adenosine-3'-phosphate } & 0 \cdot 057 \\ \text { Adenosine-5'-phosphate } & 0 \cdot 061 \\ \text { Guanine } & 0 \cdot 062 \\ \text { Guanosine } & 0 \cdot 058 \\ \text { Guanylic acid } & 0 \cdot 074 \\ \text { Xanthine } & 0 \cdot 059 \\ \text { Xanthosine } & 0.064 \\ \text { Hypoxanthine } & 0 \cdot 068 \\ \text { Inosine } & 0 \cdot 065\end{array}$

nucleosides or nucleotides (Aaronson \& Nathan, 1954); in the present study uric acid was found to be inert. When the natural purines and their nucleosides and nucleotides were compared quantitatively, it was found that only small differences in activities (on a molar basis) existed between them (Table 5). The organism appears to have efficient mechanisms for shifting substituent groupings, both oxidatively and reductively. In order further to investigate these abilities a number of unnatural purines were tested. Those unnatural purines which were not inert expressed themselves by complete replacement of a natural purine or by mild inhibition (Table 6). None showed a sparing action instead of replacement, as is so characteristic of certain purines with Tetrahymena pyriformis (Kidder \& Dewey, 1949; Kidder, Dewey, Parks \& Heinrich, 1950). The purine requirement of $C$. fasciculata was completely satisfied by 6-chloropurine, 2:6-diaminopurine, 6-(2-furfuryl amino)purine (kinetin) and 6-phenylaminopurine, although a time-lag period of greater or lesser extent always manifested itself (Table 7 ). Certain structural prerequisites 
appear to exist before this organism can shift substituent groups to form metabolically active purines. No substituted xanthine tested was utilized (uric acid, caffeine, theophylline, theobromine) and no purine substituted in the 8-position (uric acid, 8-methyladenine). No purine unsubstituted at the 6-position could satisfy the purine requirement (purine, 2-aminopurine, 2-hydroxypurine) and the order of substitution in the di-substituted purines was

Table 6. Activities of purine and substituted purines for Crithidia fasciculata

Utilized for growth

2:6-Diaminopurine

6-Chloropurine

Kinetin

6-Phenylaminopurine
Inhibition*

8-Azaguanine

6-Mercaptopurine

6-Methylpurine

Thioguanine

2-Azaadenine

1-Deazaguanine

8-Aza-2:6-diaminopurine

8-Azaxanthine

Puromycin
Inert

Isoguanine
2-Aminopurine
2-Hydroxypurine
Purine
2-Methylthio-6-aminopurine
8-Methyladenine
Theophylline
Caffeine
Theobromine
Uric acid
Puromycin aminonucleoside

* No compound except 8-azaguanine produced as much as half maximum inhibition when used in concentrations of $200 \mu \mathrm{g} . / \mathrm{ml}$.

Table 7. Replacement of natural purine (adenine) by unnatural purines

Basal Medium I minus purine.

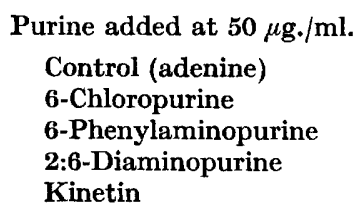

\begin{tabular}{|c|c|c|c|}
\hline \multicolumn{4}{|c|}{ Days } \\
\hline \multicolumn{4}{|c|}{ Optical density } \\
\hline 0.370 & $0 \cdot 700$ & 0.890 & 0.950 \\
\hline $0 \cdot 150$ & $0 \cdot 620$ & $0 \cdot 840$ & 0.910 \\
\hline $0 \cdot 120$ & $0 \cdot 480$ & 0.795 & 0.905 \\
\hline $0 \cdot 047$ & $0 \cdot 150$ & 0.450 & $0 \cdot 895$ \\
\hline 0.045 & $0 \cdot 145$ & 0.455 & 0.910 \\
\hline
\end{tabular}

important (i.e. guanine, xanthine and 2:6-diaminopurine were all utilized but isoguanine and 2-methylthio-6-aminopurine were not). One substitution on the amino group of adenine appeared to be successfully removed (kinetin and 6-phenylaminopurine) but not two (puromycin and puromycin nucleoside). Hydrolysis of the chlorine substituent in position 6 (6-chloropurine) appeared to be accomplished with ease but hydrolysis appeared to be impossible when either $-\mathrm{SH}$ or $-\mathrm{CH}_{3}$ was in that position.

It is interesting to note that none of the structural analogues of natural purines tested showed marked inhibition in the growth of Crithidia fasciculata. Only 8-azaguanine produced as much as half maximal inhibition and all were tested in concentrations up to $200 \mu \mathrm{g}$. $/ \mathrm{ml}$. The inhibition index (half maximal calculated with guanine) of 8 -azaguanine was over 50 , which makes it about 1000 times less efficient as an inhibitor for $C$. fasciculata than it is for Tetrahymena 


\section{Growth and nutrition of Crithidia}

pyriformis (Kidder, Dewey, Parks \& Woodside, 1949). Perhaps it is its particular type of purine metabolism which makes $C$. fasciculata almost immune to such generally inhibitory compounds as 6-methylpurine and 6-mercaptopurine.

Aaronson \& Nathan (1954) reported that Crithidia fasciculata can satisfy its purine requirement with 4-amino-5-imidazolecarboxamidine (the imidazole counterpart of adenine) but not with 4-amino-5-imidazolecarboxamide (the counterpart of hypoxanthine). We have confirmed the inactivity of the carboxamide (the carboxamidine was not re-tested) but we found that the block appears to be in the inability of the organism to add what will become the 2-carbon of hypoxanthine, for 4-formylamino-5-imidazolecarboxamide will satisfy the purine requirement. This compound is not utilized very efficiently as rather high concentrations are needed for maximal growth in the absence of other purines. Filter sterilization was used for this compound as it is known that spontaneous ring closure can take place at high temperatures. Lack of ability of $C$. fasciculata to close the imidazole ring to form a purine is shown by the fact that both 2:5:6-triamino-4-hydroxypyrimidine and 2:6-diamino4-hydroxy-5-formylaminopyrimidine are inert for this organism.

\section{Vitamins}

Cowperthwaite et al. (1953) listed seven vitamins as being required for the growth of Crithidia fasciculata but they gave no experimental details. We have confirmed their qualitative findings and have studied the quantitative aspects of the problem. In the present medium, and with care regarding depletion of the organisms for inoculation (see Methods), growth failed when thiamine, riboflavin, nicotinamide, pyridoxal and pyridoxamine, pantothenic acid or folic acid was omitted from the medium. When catalytic amounts of folic acid were present then biopterin had to be added.

Indefinitely transplantable, though suboptimal, growth occurred in media to which no biotin was added. This would indicate that some component of the medium contained biotin as a contaminant, or that the organism was synthesizing suboptimal amounts of the vitamin, or that end-products of biotincontrolled reactions were present in the medium. The last possibility was tested by the omission of aspartic acid, Tween 80 (which contains oleate) and acetate. Their omission did not influence the serial transplantability of Crithidia fasciculata in medium with no added biotin. It seems probable that there was some biotin contamination of the haemin used, since decreasing the haemin content of the medium decreased the amount of growth, and this growth was restored, within limits, by adding biotin (drastic decrease of the amount of haemin brought about a haemin deficiency which was not annulled by adding biotin). The inclusion of crystalline avidin, however, made growth impossible and this inhibition was entirely annulled by adding biotin. It seems safe to conclude that $C$. fasciculata is dependent upon an exogenous source of biotin, for the binding power of avidin is not exerted on endogenous biotin.

In Table 8 the quantities of the various vitamins required for half maximal 
growth are given. It will be seen that nicotinamide was about five times more active than the acid, and that pyridoxamine was about twenty times more active than pyridoxal. Pyridoxine was without activity.

Table 8. Quantitative requirement of vitamins for Crithidia fasciculata in Medium I (minus appropriate vitamin)

Results read after 4 days of incubation where maximum growth was represented by optical densities of $0 \cdot 670-0 \cdot 740$.

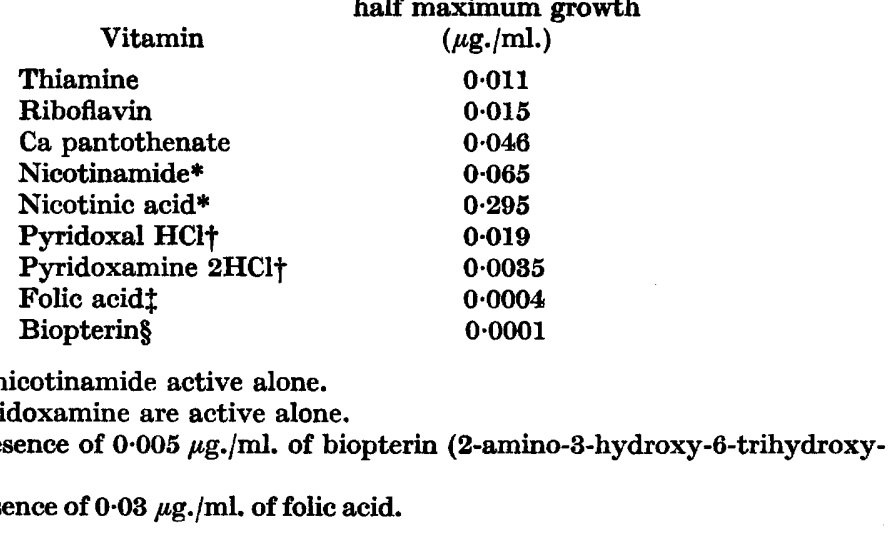

Amount required for
half maximum growth

$\mu \mathrm{g} \cdot / \mathrm{ml}$.

0.065

0.295

0.0085

$\begin{array}{ll}\text { Folic acid } \ddagger & 0.0004 \\ \text { Biopterin§ } & 0.0001\end{array}$

*Nicotinic acid or nicotinamide active alone.

$\uparrow$ Pyridoxal or pyridoxamine are active alone.

\# Tested in the presence of $0.005 \mu \mathrm{g}$. $/ \mathrm{ml}$. of biopterin (2-amino-3-hydroxy-6-trihydroxypropyl pteridine).

8 Tested in the presence of $0.03 \mu \mathrm{g} . / \mathrm{ml}$. of folic acid.

While folic acid alone will support the growth of Crithidia fasciculata (Cowperthwaite et al. 1953) relatively extremely high concentrations are required. On the other hand, high concentrations of biopterin (with no folic acid present) did not support growth. When the two were present together then low concentrations of each produced maximal growth (Table 8; Fig. 4). A comparison of the activities of various 2-amino-4-hydroxy-6-alkylpteridines (these compounds were kindly supplied by Drs H. P. Broquist and E.L.R. Stokstad, Lederle Division, American Cyanamid Co., Pearl River, N.Y.) for biopterin activity disclosed that the one isolated from urine (Patterson et al. 1955) and the synthetic biopterin (2-amino-4-hydroxy-6-erythrotrihydroxypropyl pteridine) were equal, but that 2-amino-4-hydroxy-6-(D-threo-1 $\mathbf{1}^{\prime}: 2^{\prime}$-dihydroxypropyl)pteridine (sent by Professor M. Viscontini for activity assay) had only slight biopterin activity. The $\mathrm{HB}_{2}$ Drosophila pteridine of Viscontini, Loeser, Karrer \& Hadorn (1955; sent by Professor M. Viscontini) proved to be four times more active than the biopterin from urine. When the trihydroxypropyl biopterin is oxidized in position 7 (7-oxybiopterin, supplied by Professor R. Tschedsche) then all activity was lost. These observations add to our knowledge of the specificity of the molecule for biopterin activity beyond that which was previously published by Patterson et al. (1955).

It appears that Crithidia fasciculata is very inefficient, but not entirely deficient in mechanisms for cleaving a conjugated pteridine to an unconjugated pteridine but has no ability to construct folic acid. This is borne out by the observation that pteroic acid can supply the biopterin requirement if 


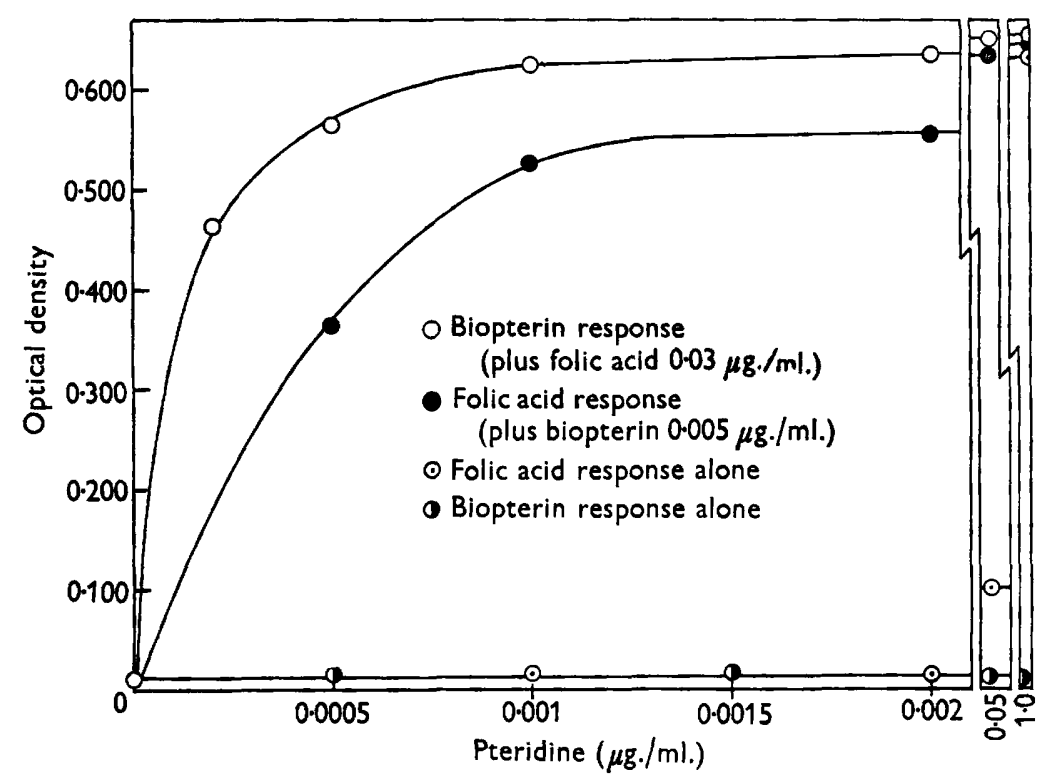

Fig. 4. Dose response of Crithidia fasciculata to biopterin (2-amino-4-hydroxy-6-erythrotrihydroxypropyl pteridine) and to folic acid. Inoculum was from 10-day culture in low $(0.001 \mu \mathrm{g} . / \mathrm{ml}$.) folic acid and no biopterin.

Table 9. Growth response of Crithidia fasciculata to folic acid and pteroic acid in the presence and absence of biopterin

Four-day growth.

\begin{tabular}{ccccc} 
& \multicolumn{4}{c}{ Optical density } \\
\cline { 2 - 5 } $\begin{array}{c}\text { Amount added } \\
(\mu \mathrm{g} . / \mathrm{ml} .)\end{array}$ & Folic acid & Pteroic acid & $\begin{array}{c}\text { Folic acid } \\
+ \text { biopterin* }\end{array}$ & $\begin{array}{c}\text { Pteroic acid } \\
\text { + biopterin* }\end{array}$ \\
0 & 0.033 & 0.027 & 0.044 & 0.043 \\
0.001 & 0.038 & 0.026 & 0.495 & 0.054 \\
0.01 & 0.052 & 0.034 & 0.543 & 0.297 \\
0.1 & 0.290 & 0.392 & 0.580 & 0.425 \\
1.0 & 0.577 & 0.543 & 0.633 & 0.578 \\
& & $0.0003 \mu \mathrm{g} . / \mathrm{ml}$. &
\end{tabular}

present in high concentrations (Table 9), but cannot act catalytically with added biopterin, as folic acid does. Growth with pteroic acid and biopterin is limited to the contamination of the pteroic acid with small quantities of folic acid (traces of folic acid were found by the use of paper chromatography in all of our samples of pteroic acid) when low levels are used (Table 10).

As reported by Nathan et al. (1956), the folic acid requirement can be by-passed by the addition of thymine or thymidine, provided methionine (not homocysteine, etc.) is present in the medium. The optimum amount of thymine or thymidine which had to be added to a biopterin-containing medium was about $25 \mu \mathrm{g} . / \mathrm{ml}$, as the nucleoside was about twice as active as the free 
base on a molar basis. With either thymine or thymidine growth never reached maximal values (Table 11), and the degree of growth did not change with longer incubation periods.

Table 10. Growth response of Crithidia fasciculata to increasing amounts of biopterin in the presence of folic acid and pteroic acid

Four-day growth.

$\begin{gathered}\text { Biopterin } \\ (\mu \mathrm{g} . / \mathrm{ml} .)\end{gathered}$
$\mathbf{0}$
$\mathbf{0} 0001$
$\mathbf{0 . 0 0 0 2}$
$\mathbf{0 . 0 0 0 5}$
$\mathbf{0} \cdot 1$

\begin{tabular}{|c|c|}
\hline \multicolumn{2}{|c|}{ Optical density } \\
\hline $\begin{array}{c}\text { Folic acid } \\
0.005 \mu \mathrm{g} . / \mathrm{ml} \text {. }\end{array}$ & $\begin{array}{l}\text { Pteroic acid } \\
0.005 \mu \mathrm{g} . / \mathrm{ml}\end{array}$ \\
\hline 0.022 & 0.013 \\
\hline $0 \cdot 390$ & $0 \cdot 260$ \\
\hline 0.570 & 0.200 \\
\hline $0 \cdot 630$ & $0 \cdot 210$ \\
\hline $0 \cdot 684$ & $0 \cdot 213$ \\
\hline
\end{tabular}

Table 11. Growth response of Crithidia fasciculata to increasing amounts of biopterin in the presence of folic acid, thymine and thymidine

Basal medium contained optimal amounts of methionine, serine and purine. Five-day growth.

\begin{tabular}{lccc} 
& \multicolumn{3}{c}{ Optical density } \\
Biopterin & $\overbrace{\text { Folic acid, }}$ & Thymine, & Thymidine, \\
$(\mu \mathrm{g} . / \mathrm{ml})$. & $0.002 \mu \mathrm{g} . / \mathrm{ml}$. & $40 \mu \mathrm{g} . / \mathrm{ml}$. & $40 \mathrm{mg} . / \mathrm{ml}$. \\
0 & 0.016 & 0.052 & 0.031 \\
0.0001 & 0.270 & 0.337 & 0.382 \\
0.005 & 0.670 & 0.394 & 0.431 \\
1.0 & 0.687 & 0.437 & 0.467
\end{tabular}

Following the suggestion of Nathan et al. (1956), we tested the effect of high concentrations of riboflavin on the biopterin requirement of Crithidia fasciculata. In the present medium riboflavin at as high as $5-10 \mu \mathrm{g} . / \mathrm{ml}$. had a slight sparing effect on biopterin, but as both compounds were absolute requirements and the sparing effect was low, it seems improbable that the scheme presented by Nathan et al. (1956) for the interrelationships of the two can be fully accepted.

\section{DISCUSSION}

As previously stated, we were unable to obtain satisfactory growth of Crithidia fasciculata in the medium proposed by Nathan \& Cowperthwaite (1954). It now is apparent that the deficiencies of this medium are multiple. The total amino acid concentrations are too low for this organism, and we have had to add over five times the concentration of the essential amino acids that was suggested (Table 12). The omission of threonine from their medium brings about a very serious deficiency. Less important differences between their medium and ours (Medium II) include suboptimal purine, folic acid and isoleucine and the absence of Tween. 
After the above experimental work was completed we have used the inorganic salt concentrations suggested by Newton (1956) and have thereby been able to simplify that portion of the present medium. While there is slight precipitation of the salts, as this mixture contains no ethylenediaminetetraacetic acid, growth of Crithidia fasciculata was excellent.

Table 12. Comparison of amino acid concentrations $(\mu \mathrm{g} . / \mathrm{ml}$.) of the medium of Nathan \& Cowperthwaite (1954) with those of the present Medium II

\begin{tabular}{lcc}
\multicolumn{1}{c}{ Amino acid } & N. \& C. & Medium II \\
L-Arginine HCl & $\mathbf{2 5 0}$ & $\mathbf{4 3 0}$ \\
L-Histidine HCl & $\mathbf{2 0 0}$ & $\mathbf{2 1 0}$ \\
DL-Isoleucine & $\mathbf{5 0}$ & $\mathbf{6 3 0}$ \\
DL-Leucine & $\mathbf{5 0}$ & - \\
L-Leucine & - & $\mathbf{9 7 0}$ \\
DL-Lysine & $\mathbf{2 0 0}$ & - \\
L-Lysine & - & $\mathbf{7 6 0}$ \\
DL-Methionine & $\mathbf{8 0}$ & $\mathbf{3 4 0}$ \\
DL-Phenylalanine & $\mathbf{4 0}$ & - \\
L-Phenylalanine & - & $\mathbf{5 0 0}$ \\
DL-Tryptophan & $\mathbf{2 0}$ & - \\
L-Tryptophan & - & $\mathbf{1 2 0}$ \\
L-Tyrosine & $\mathbf{5 0}$ & - \\
L-Tyrosine ethyl ester & - & $\mathbf{2 0 0}$ \\
DL-Valine & $\mathbf{5 0}$ & $\mathbf{6 6 0}$ \\
DL-Threonine & \multicolumn{4}{|c|}{ Total } & $\mathbf{9 9 0}$ & $\mathbf{5 2 6 0}$
\end{tabular}

The nutritional pattern of Crithidia fasciculata regarding amino acids differs only in minor details from that of other animals. The ability to replace methionine with cysteine and cystathionine is unusual, although the ability to transmethylate homocysteine is widespread. This transmethylation is not possible in Tetrahymena pyriformis (geleii) (Genghof, 1949). The fact that citrulline, but not ornithine, can replace arginine for this organism makes it similar to certain stocks of Drosophila (Hinton, Noyes \& Ellis, 1951 ; Hinton, 1956) and quite different for Tetrahymena pyriformis (Dewey et al. 1957).

The requirement for a pre-formed purine has been found to be rather widespread among bacteria, moulds and protozoa. In the latter group a particular purine is often needed (Kidder \& Dewey, 1949; Kidder et al. 1950; Kidder \& Dewey, 1955; Miller \& Johnson, 1957) while purine-requiring bacteria most frequently will utilize any one of a number of purines (Pearson, 1949; Guthrie, 1949; Gots, 1957). In this respect, therefore, Crithidia fasciculata resembles the bacterial types rather than the ciliates. We do not know at present the specific pathways used by $C$. fasciculata for the interconversions of purines, but it is obvious that they can both reduce and oxidize at position 2 on the ring, provided position 6 is correctly substituted. A curious situation exists regarding isoguanine (2-hydroxy-6-aminopurine). Mechanisms appear to be absent for handling this compound, although 2:6-diaminopurine and xanthine are readily used. Gots (1957) reported the exact reverse situation in a purineless mutant of Escherichia coli where isoguanine, but not 2:6-diaminopurine was utilized. 
There appears to be no lack of functional enzymes in Crithidia fasciculata for attaching and removing sugar and sugar phosphates, as bases, nucleosides and nucleotides are all about equally active. At the present time there is no indication as to the stage (base, nucleoside, nucleotide) at which the shifting of substituent groups on the purine ring occurs.

The qualitative requirements for the water-soluble vitamins are not unusual except for the pteridines. It should be pointed out that Crithidia fasciculata resembles the ciliates (Kidder, Dewey, Andrews \& Kidder, 1949) in its failure to synthesize nicotinic acid from tryptophan, for both the amino acid and the vitamin are absolute requirements.

It would appear that the enzymes necessary for the cleavage of folic acid to the unconjugated pteridine are very inefficient, so that extremely high concentrations of the conjugated forms (folic acid and pteroic acid) must be present before active levels of biopterin can be produced. There can be no question of the importance of a folic acid coenzyme function, however, as distinct from a biopterin coenzyme function, for no amount of biopterin will permit growth in the absence of thymine or methionine. Even when both of these common products of one carbon transfer reactions are provided, growth is suboptimal. It seems probable, as suggested by van Baalen, Forrest \& Myers (1957), that neither the dihydroxypropyl nor the trihydroxypropyl biopterins are the naturally active forms of the unconjugated pteridines, but more active forms can be synthesized from them by this organism. The $\mathrm{HB}_{2}$ Drosophila factor, for instance, is four times as active as the biopterins on a weight basis and its molecular weight must be larger, not smaller.

At present there is no evidence as to the metabolic function of the unconjugated pteridines, but their widespread occurrence in nature would suggest that they will ultimately be found to have great metabolic significance. Inasmuch as Crithidia fasciculata has a requirement for unconjugated pteridines, and is the only organism so far known with such a requirement, it may now be employed for a study along these lines.

This investigation was supported by research grants (A-1005 and CY-294) from the National Institutes of Health, U.S. Public Health Service.

\section{REFERENCES}

Aaronson, S. \& Nathan, H. A. (1954). Utilization of imadazole counterparts of purines in microbial systems. Biochem. biophys. Acta, 15, 306.

Broquist, H. P. \& Albrecht, A. M. (1955). Pteridines and nutrition of the protozoon Crithidia fasciculata. Proc. Soc. exp. Biol., N.Y. 89, 178.

Cowperthwaite, J., Weber, M. M., Packer, L. \& Hutner, S. H. (1958). Nutrition of Herpetomonas (Strigomonas) culicidarum. Ann. N.Y. Acad. Sci. 56, 972.

Dewey, V. C., Heinrich, M. R. \& Kidder, G. W. (1957). Evidence for the absence of the urea cycle in Tetrahymena. J. Protozool. 4, 211.

Dewey, V. C., PArks, R. E., Jr. \& Kidder, G. W.(1950). Growth responses of Tetrahymena geleii to changes in the basal media. Arch. Biochem. 29, 281.

GenghoF, D. S. (1949). The sulfur amino acid requirement of Tetrahymena geleii. Arch. Biochem. 23, 85. 
Gots, J. S. (1957). Purine metabolism in bacteria. V. Feed-back inhibition. J. biol. Chem. 228, 57.

GUThRIE, R. (1949). Studies of a purine-requiring mutant strain of Escherichia coli. J. Bact. 57, 39.

Hinton, T. (1956). The effect of arginine, ornithine and citrulline on the growth of Drosophila. Arch. Biochem. Biophys. 62, 78.

Hrnton, T., Noyes, D. T. \& Elurs, J. (1951). Amino acids and growth factors in a chemically defined medium for Drosophila. Physiol. Zool. 24, 335.

Hutner, S. H. \& Provasoli, L. (1955). Comparative biochemistry of flagellates. In Biochemistry and Physiology of Protozoa. Ed. by S. H. Hutner and A. Lwoff. New York: Academic Press.

Johnson, W. H. \& Mrluer, C. A. (1956). A further analysis of the nutrition of Paramecium. J. Protozool. 3, 221.

KIDDER, G. W. \& Dewey, V. C. (1948). Dietary factors in the utilization of homocystine. Proc. nat. Acad. Sci., Wash. 34, 81.

KIDDER, G. W. \& Dewey, V. C. (1949). The biological activity of substituted purines. J. biol. Chem. 179, 181.

KIDDER, G. W. \& DEWEy, V. C. (1951). The biochemistry of ciliates in pure culture. In Biochemistry and Physiology of Protozoa. Ed. by A. Lwoff. New York : Academic Press.

KIDDER, G. W. \& Dewey, V. C. (1955). The purine and pyrimidine requirements of Glaucoma scintillans. Arch. Biochem. Biophys, 55, 126.

Kidder, G. W., Dewey, V. C., ANdrews, M. B. \& Kidder, R. R. (1949). Tryptophan and nicotinamide in the nutrition of the animal microorganism, Tetrahymena. J. Nutr. 37, 521.

Kidder, G. W., Dewey, V. C. \& Heinrich, M. R. (1954). The effect of non-ionic detergents on the growth of Tetrahymena Exp. Cell. Res. 7, 256.

Kidder, G. W., Dewey, V. C., Parks, R. E., Jr. \& Heinrich, M. R. (1950). Further studies on the purine and pyrimidine metabolism of Tetrahymena. Proc. nat. Acad. Sci., Wash. 36, 431.

Kidder, G. W., Dewey, V. C., Parks, R. E., Jr. \& Woodside, G. L. (1949). Purine metabolism in Tetrahymena and its relation to malignant cells in mice. Science, 109, 511.

KIDDER, G. W. \& Fuller, R. C. (1946). The growth response of Tetrahymena geleii $\mathrm{W}$ to folic acid and to the Streptococcus lactis $\mathrm{R}$ factor. Science, 104, 160.

Lin, S. C. \& Greengerg, D. M. (1954). Enzymatic breakdown of threonine by threonine aldolase. J. gen. Physiol. 38, 181.

Lwoff, M. (1933). Recherches sur la nutrition des trypanosomides. Ann. Inst. Pasteur, $51,55$.

Mruler, C. A. \& Johnson, W. H. (1957). A purine and pyrimidine requirement for Paramecium multimicronucleatum. J. Protozool. 4, 200.

Miluer, C. A. \& van Wagtendonk, W. J. (1956). The essential metabolites of a strain of Paramecium aurelia (stock 47-8) and a comparison of the growth rate of different strains of Paramecium aurelia in axenic culture. J. gen. Microbiol. $15,280$.

Nathan, H. A. \& Cowperthwatte, J. (1954). Use of the trypanosomid flagellate, Crithidia fasciculata, for evaluating antimalarials. Proc. Soc. exp. Biol., N.Y. $85,117$.

Nathan, H. A. \& Cowperthwate, J. (1955). 'Crithidia Factor'. A new member of the folic acid group of vitamins. J. Protozool. 2, 37.

Nathan, H. A., HUTner, S. H. \& Levin, H. L. (1956). Independent requirements for 'Crithidia Factor' and folic acid in a trypanosomid flagellate. Nature, Lond. 178, 74.1.

Newron, B. A. (1956). A synthetic growth medium for the trypanosomid flagellate Strigomonas (Herpetomonas) oncopelti. Nature, Lond. 177, 279. 
Nrelands, J. B. (1952). A crystalline organo-iron pigment from a rust fungus (Ustilago sphaerogena). J. Amer. chem. Soc. 74, 4846.

Nielands, J. B. (1953). Biological properties of ferrichrome. Fed. Proc. 12, 250.

Patterson, E. L., Broquist, H. P., Albrecht, A. M., von Saltza, M. H. \& StokSTAD, E. L. R. (1955). A new pteridine in urine required for the growth of the protozoon Crithidia fasciculata. J. Amer. chem. Soc. 77, 3167.

Pearson, W. N. (1949). A purine requiring strain of Photobacterium fischeri. J. Bact. 58, 653.

Trager, W. (1956). Nutritional requirements of the leptomonads of a hemoflagellate from lizards (Leishmania tarentolae). J. Protozool. (Suppl.), 3, 6.

Van BaAlen, C., Forrest, H. S. \& MYers, J. (1957). Incorporation of radioactive carbon into a pteridine of a blue-green alga. Proc. nat. Acad. Sci., Wash. 43, 701.

Viscontini, M., Loeser, E., Karrer, P. \& Hadorn, E. (1955). Fluoreszierende Stoffe aus Drosophila melanogaster. Helv. chim. Acta. 38, 2034.

WALlace, F. G. (1943). Flagellate parasites of mosquitoes with special reference to Crithidia fasciculata Léger, 1902. J. Parasitol. 29, 196.

(Received 18 November 1957) 